\title{
The additional value of integrated PET/CT over PET in initial lymph node staging of esophageal cancer
}

\author{
HIROYUKI KATO $^{1}$, HITOSHI KIMURA ${ }^{1}$, MASANOBU NAKAJIMA ${ }^{1}$, MAKOTO SAKAI $^{1}$, \\ AKIHIKO SANO ${ }^{1}$, NARITAKA TANAKA ${ }^{1}$, TAKANORI INOSE ${ }^{1}$, AHMAD FARIED ${ }^{1}$, \\ KANA SAITO $^{1}$, KEISUKE IETA ${ }^{1}$, MAKOTO SOHDA ${ }^{1}$, YASUYUKI FUKAI ${ }^{1}$, \\ TATSUYA MIYAZAKI ${ }^{1}$, NORIHIRO MASUDA ${ }^{1}$, MINORU FUKUCHI ${ }^{1}$, HITOSHI OJIMA ${ }^{1}$, \\ KATSUHIKO TSUKADA ${ }^{1}$, NOBORU ORIUCHI ${ }^{2}$, KEIGO ENDO ${ }^{2}$ and HIROYUKI KUWANO ${ }^{1}$ \\ ${ }^{1}$ Departments of General Surgical Science (Surgery I) and ${ }^{2}$ Diagnostic Radiology and Nuclear Medicine, \\ Gunma University, Graduate School of Medicine, 3-39-22, Showa-machi, Maebashi, Gunma 371-8511, Japan
}

Received March 18, 2008; Accepted June 24, 2008

DOI: 10.3892/or_00000083

\begin{abstract}
The purpose of the present study was to assess the contribution of simultaneous functional/anatomical imaging using integrated ${ }^{18} \mathrm{~F}$-fluorodeoxyglucose-positron emission tomography/computed tomography (FDG-PET/CT), compared with PET alone for the evaluation of initial lymph node staging in esophageal cancer. We studied 167 consecutive patients with thoracic esophageal squamous cell carcinoma (SCC) who had radical esophagectomy performed between January 1999 and April 2007. For individual nodal group evaluation, PET/CT showed $46.0 \%$ sensitivity ( $\mathrm{p}<0.05$ vs. PET), $99.4 \%$ specificity, $95.1 \%$ accuracy ( $p<0.05$ vs. PET), $87.0 \%$ positive and $95.5 \%$ negative predictive values. PET showed $32.9 \%$ sensitivity, $98.9 \%$ specificity, $93.1 \%$ accuracy, $74.7 \%$ positive predictive value and $93.9 \%$ negative predictive value. Thus, the sensitivity and accuracy of PET/CT were significantly higher than those of PET. Comparisons between CT, PET and PET/CT in detecting lymph node metastasis by each region showed that PET/CT had a higher sensitivity in lower thoracic regions than PET and CT ( $<<0.05$ vs. CT and PET). Lymph node staging (N0 vs. N1) was not significantly different, but staging per lymph nodal group was significantly better with PET/CT. Integrated $\mathrm{PET} / \mathrm{CT}$ imaging with co-registration of anatomic and functional imaging data is useful in the initial lymph node staging of patients with operable esophageal cancer compared with PET alone.
\end{abstract}

Correspondence to: Dr Hiroyuki Kato, Department of General Surgical Science (Surgery I), Gunma University, Graduate School of Medicine, 3-39-22, Showa-machi, Maebashi, Gunma 371-8511, Japan

E-mail: hiroyuki@po.wind.ne.jp

Key words: esophageal cancer, ${ }^{18} \mathrm{~F}$-fluorodeoxyglucose, positron emission tomography, computed tomography, lymph node staging

\section{Introduction}

Positron emission tomography (PET) with ${ }^{18} \mathrm{~F}$-fluorodeoxyglucose (FDG) provides physiological information that enables a diagnosis of cancer based on altered tissue glucose metabolism (1). The role and potential value of PET as a non-invasive imaging modality has been widely investigated (2-5). Several studies have shown markedly increased FDG uptake in esophageal carcinoma (6-13). FDG-PET imaging may facilitate a diagnosis in patients with malignant diseases by enabling the differentiation between benign and malignant tumors, assessment of the extension of disease (6-13), detection of tumor recurrence (14-16) and monitoring response to therapy (17-20). We have previously reported the usefulness of FDG-PET for staging of esophageal squamous cell carcinoma (SCC), where it offers higher sensitivity, specificity and accuracy for lymph node detection compared to computed tomography (CT), particularly in the neck and upper thoracic region (21). With regard to staging accuracy, the incremental value of FDG-PET is $14 \%$ compared with CT $(22,23)$. Furthermore, serial FDG-PET may be of considerable value in predicting the pathological response of esophageal SCC to preoperative therapy (20).

Co-registration of PET and CT using integrated PET/CT systems has been shown to be of additional value for image interpretation of the two modalities, providing complementary information for both techniques. Improved accuracy of FDG imaging, resulting in a clinical impact on patient management, has been described with the use of PET/CT in patients with lung, colon, head and neck tumors, lymphomas and esophagus (24-30). Integrated PET/CT has been shown to be more useful than PET and CT performed separately (31). Integrated PET/CT imaging facilitates the separation of normal physiological uptake from pathological uptake, allows accurate localization of functional abnormalities and reduces the incidence of false-positive and false-negative imaging studies (31). PET/CT has been shown to decrease the number of false-positive findings compared to PET alone by anatomical correlation, though differentiation of inflammation 
from malignancy must still be considered a limitation of FDG-PET and PET/CT.

Accurate preoperative staging, particularly with regard to the depth of tumor invasion, involvement of lymph nodes and distant metastasis, is vital in determining the most appropriate procedures for curative surgery for thoracic esophageal carcinoma (21). Regional lymph node metastasis is one of the most important prognostic factors and has a major impact on treatment selection in esophageal cancer (23). Both the number and the location of involved lymph nodes have been considered to be important prognostic factors (12). However, PET alone has a low sensitivity for initial nodal staging $(10-13,22)$. The purpose of the present study was to assess the contribution of simultaneous functional/anatomical imaging using integrated FDG-PET/CT, compared with PET alone, for the evaluation of initial lymph node staging in esophageal cancer. We hypothesized that integrated PET/CT would be of additional value over conventional PET images.

\section{Patients and methods}

Patients. We studied 167 consecutive patients with thoracic esophageal SCC who had radical esophagectomy performed at the Department of General Surgical Science, Graduate School of Medicine, Gunma University, Japan, between January 1999 and April 2007. None of the patients had received prior treatment. The median age was 64.1 years, with a range of 41-79 years (Table I). Tumor stage and disease grade were classified according to the sixth edition of the TNM classification of the International Union Against Cancer (UICC) (32). We determined the tumor stage conventionally by $\mathrm{CT}$ of the neck, chest, and abdomen, bone scans, endoscopic ultrasound (EUS), endoscopy and esophagography. The blood sugar levels in all patients were $<120 \mathrm{mg} / \mathrm{dl}$ at the time of the PET scan.

Treatment and clinical outcome. Two different procedures were used. In suitable patients, a standard esophagectomy was performed by the McKeown method and three-field (thoracoabdominal and cervical) lymph node dissection was also performed if indicated. In other patients, Ivor Lewis esophagectomy was used and two-field (thoracoabdominal) lymph node dissection was performed. All patients underwent curative thoracic esophagectomy that included the esophagogastric junction (21). After surgery, the lymph nodes were separated from the resected esophagus and the adjacent tissue and were assigned specific numbers indicating the localization of the lymph node, according to the guidelines of the Japanese Society for Esophageal Diseases (JSED) (33).

PET imaging. All patients underwent PET before surgery for staging at initial diagnosis. We studied 117 patients with thoracic esophageal SCC using PET images between 1999 and 2005. We also studied 50 patients using integrated PET/CT between 2006 and 2007 (Table I).

We obtained PET images using a SET $2400 \mathrm{~W}$ (Shimadzu Corporation, Kyoto, Japan) with a 59.5-cm transaxial field of view and a $20-\mathrm{cm}$ axial field of view. A whole-body image was initiated $40 \mathrm{~min}$ after the injection of FDG using the simultaneous emission/transmission method (21). Between four and five sections were imaged from head to thigh for a period of 8 min per section. Patients fasted for at least $4 \mathrm{~h}$ before FDG-PET. Our Institutional Review Board approved the imaging protocols (21) and all patients gave informed consent before undergoing the examination. Two experienced nuclear medicine physicians evaluated all PET images qualitatively. Functional images of standardized uptake value (SUV) were produced from the attenuation-corrected transaxial images, the amount of injected FDG, body weight and the cross-calibration factors between PET and the dose calibrator. SUV was defined as the concentration of radioactivity in the tissue or lesion $(\mathrm{MBq} / \mathrm{ml}) \mathrm{x}$ patient body weight $(\mathrm{g})$ / injected dose $(\mathrm{MBq})$. Regional lymph nodes, which were evaluated using PET, were assigned specific numbers to indicate localization, in accordance with the guidelines of the Japanese Society for Esophageal Diseases (JSED). We obtained PET/CT images using a hybrid PET/CT system (GE Discovery ST8, GE, Milwaukee, USA) for eight-slice, helical CT acquisition, followed by a full-ring dedicated PET scan of the same axial range. Both PET and CT were performed with normal tidal breathing. PET images were reconstructed using ordered subset expectation maximization (OSEM) software, using CT-derived attenuation correction. The attenuation-corrected PET images, the CT images and the fused PET/CT images were available for review in axial, coronal and sagittal planes, as was a cine display of maximum intensity projections (MIP) of the PET data, using the manufacturer's review station (eNTegra and Xeleris, GEMS, Milwaukee, USA).

CT scan. Between 1999 and 2005, all 117 patients underwent a helical CT scan of the neck, chest and abdomen before surgery for staging at initial diagnosis. Ten-millimeter continuous scans were obtained from the neck to the bottom of the liver. A helical CT scanner was used and scanning was performed before and after injection of an intravenous contrast medium 3 min later. An oral contrast was not used. Lymph nodes were considered positive for metastasis if the short axis was $>1 \mathrm{~cm}$. These positive lymph nodes were assigned a specific number to indicate localization according to the guidelines of the JSED. The CT scan hard copy images were interpreted by two radiologists who were blinded to the results of the PET scan.

Statistical analysis. The sensitivity, specificity, accuracy, positive predictive value (PPV) and negative predictive value (NPV) of CT, PET and PET/CT were calculated using the standard definitions (34). The accuracy of CT, PET and PET/CT was compared using a McNemar test (35). The relationships between each treatment and the clinical features were determined using the $\chi^{2}$ method and Fisher's exact test. The relationship between other parameters and SUV was determined using analysis of variance (ANOVA) or the student's t-test.

\section{Results}

Primary tumor. The primary tumor was visualized in 87 (74\%) of 117 patients by PET imaging and in $41(82 \%)$ of 50 patients by PET/CT ( $\mathrm{p}=0.2851)$. Using PET imaging, FDG uptake was 
Table I. Patient characteristics.

\begin{tabular}{|c|c|c|c|c|}
\hline Parameter & No. $(n=167)$ & $\operatorname{PET}(n=117)$ & PET/CT $(n=50)$ & P-value \\
\hline \multicolumn{5}{|l|}{ Gender } \\
\hline Male & 154 & 106 & 48 & 0.2328 \\
\hline Female & 13 & 11 & 2 & \\
\hline \multicolumn{5}{|l|}{ Age (years) } \\
\hline (Ave) & 64.1 & 63.9 & 64.4 & 0.7373 \\
\hline (Range) & $(41-79)$ & $(41-79)$ & $(49-78)$ & \\
\hline \multicolumn{5}{|l|}{ Location } \\
\hline Upper & 22 & 15 & 7 & 0.9132 \\
\hline Middle & 81 & 58 & 23 & \\
\hline Lower & 64 & 44 & 20 & \\
\hline \multicolumn{5}{|c|}{ Tumor classification } \\
\hline $\mathrm{T} 1$ & 76 & 55 & 21 & 0.7957 \\
\hline $\mathrm{T} 2$ & 13 & 8 & 5 & \\
\hline T3 & 69 & 47 & 22 & \\
\hline $\mathrm{T} 4$ & 9 & 7 & 2 & \\
\hline \multicolumn{5}{|c|}{ Lymph node status } \\
\hline No & 78 & 57 & 21 & 0.4255 \\
\hline N1 & 89 & 60 & 29 & \\
\hline \multicolumn{5}{|c|}{ Metastatic status } \\
\hline M0 & 137 & 97 & 40 & 0.6567 \\
\hline M1 & 30 & 20 & 10 & \\
\hline \multicolumn{5}{|l|}{ Stage } \\
\hline I & 52 & 40 & 12 & 0.4769 \\
\hline II & 49 & 31 & 18 & \\
\hline III & 36 & 26 & 10 & \\
\hline IV & 30 & 20 & 10 & \\
\hline
\end{tabular}

detected in $27(49 \%)$ of $55 \mathrm{~T} 1$ patients, $7(88 \%)$ of $8 \mathrm{~T} 2$ patients, $46(98 \%)$ of $47 \mathrm{~T} 3$ patients and $7(100 \%)$ of $7 \mathrm{~T} 4$ patients. Using PET/CT imaging, FDG uptake was detected in $12(52 \%)$ of $21 \mathrm{~T} 1$ patients, $5(100 \%)$ of $5 \mathrm{~T} 2$ patients, $22(100 \%)$ of $22 \mathrm{~T} 3$ patients and $2(100 \%)$ of $2 \mathrm{~T} 4$ patients (Fig. 1).

Lymph node status. The diagnostic accuracy of lymph node metastasis is summarized in Table II. Of the 117 patients who had PET imaging, 60 were confirmed as having lymph node metastasis histopathologically. For the evaluation of lymph node staging in the detection of lymph node metastasis, PET showed $55.0 \%$ sensitivity, $86.0 \%$ specificity, $70.1 \%$ accuracy, 80.5\% PPV and $64.5 \%$ NPV. CT showed $48.3 \%$ sensitivity, $73.7 \%$ specificity, $60.7 \%$ accuracy, $65.9 \%$ PPV and $57.5 \%$ NPV (Table II). Of the 50 patients who had PET/CT imaging, 29 were confirmed to have lymph node metastasis histopathologically. For the evaluation of lymph node staging in the detection of lymph node metastasis, PET/CT showed $75.9 \%$ sensitivity ( $\mathrm{p}<0.05$ vs. CT), $81.0 \%$ specificity, $78.0 \%$ accuracy ( $<<0.05$ vs. CT), $84.6 \%$ PPV and $70.8 \%$ NPV. There was no significant difference between PET and PET/CT for lymph node staging evaluation.
During surgery, the total number of dissected lymph nodes for the 117 patients by PET imaging was 8090, with an average of 69 dissected lymph nodes per patient. These lymph nodes comprised of 2332 cervical, 3454 thoracic and 2304 abdominal nodes. We found 1936 lymph node groups according to the JSED classification in 117 patients. Histopathologically, nodal metastases were present in 265 nodes and in 170 lymph node groups. The diagnostic sensitivity, specificity and accuracy of PET and CT for lymph node metastasis are shown in Table II. For individual nodal group evaluation, PET showed $32.9 \%$ sensitivity, $98.9 \%$ specificity, 93.1\% accuracy, $74.7 \%$ PPV and $93.9 \%$ NPV. CT showed $26.5 \%$ sensitivity, $97.5 \%$ specificity, $91.3 \%$ accuracy, $50.1 \%$ PPV and 93.2\% NPV. The specificity, accuracy and PPV of PET were significantly higher than those of $\mathrm{CT}(\mathrm{p}<0.01$, $\mathrm{p}<0.05$ and $\mathrm{p}<0.01$, respectively).

In the 50 patients using PET/CT imaging, the total number of dissected lymph nodes was 3974, with an average of 79 dissected lymph nodes per patient. These lymph nodes comprised of 1327 cervical, 1745 thoracic and 902 abdominal nodes. We found 1079 lymph node groups according to the JSED classification in 50 patients. Histopathologically, nodal metastases were present in 176 nodes, 
Table II. Diagnostic accuracy of lymph node metastasis of esophageal cancer.

\begin{tabular}{|c|c|c|c|c|c|}
\hline \multicolumn{6}{|c|}{ Staging accuracy (N0/N1) } \\
\hline & Sensitivity & Specificity & Accuracy & PPV & NPV \\
\hline $\mathrm{CT}(\mathrm{n}=117)$ & $\begin{array}{c}48.3 \\
(29 / 60)\end{array}$ & $\begin{array}{c}73.7 \\
(42 / 57)\end{array}$ & $\begin{array}{c}60.7 \\
(71 / 117)\end{array}$ & $\begin{array}{c}65.9 \\
(29 / 44)\end{array}$ & $\begin{array}{c}57.5 \\
(42 / 73)\end{array}$ \\
\hline PET (n=117) & $\begin{array}{c}55.0 \\
(33 / 60)\end{array}$ & $\begin{array}{c}86.0 \\
(49 / 57)\end{array}$ & $\begin{array}{c}70.1 \\
(82 / 117)\end{array}$ & $\begin{array}{c}80.5 \\
(33 / 41)\end{array}$ & $\begin{array}{c}64.5 \\
(49 / 76)\end{array}$ \\
\hline $\mathrm{PET} / \mathrm{CT}(\mathrm{n}=50)$ & $\begin{array}{c}75.9^{\mathrm{a}} \\
(22 / 29)\end{array}$ & $\begin{array}{c}81.0 \\
(17 / 21)\end{array}$ & $\begin{array}{c}78.0^{\mathrm{a}} \\
(39 / 50)\end{array}$ & $\begin{array}{c}84.6 \\
(22 / 26)\end{array}$ & $\begin{array}{c}70.8 \\
(17 / 24)\end{array}$ \\
\hline \multicolumn{6}{|c|}{ Lymph node group accuracy } \\
\hline & Sensitivity & Specificity & Accuracy & PPV & NPV \\
\hline $\mathrm{CT}(\mathrm{n}=117)$ & $\begin{array}{c}26.5 \\
(45 / 170)\end{array}$ & $\begin{array}{c}97.5 \\
(1722 / 1766)\end{array}$ & $\begin{array}{c}91.3 \\
(1767 / 1936)\end{array}$ & $\begin{array}{c}50.1 \\
(45 / 89)\end{array}$ & $\begin{array}{c}93.2 \\
(1722 / 1847)\end{array}$ \\
\hline PET (n=117) & $\begin{array}{c}32.9 \\
(56 / 170)\end{array}$ & $\begin{array}{c}98.9^{\mathrm{b}} \\
(1747 / 1766)\end{array}$ & $\begin{array}{c}93.1^{\mathrm{a}} \\
(1803 / 1936)\end{array}$ & $\begin{array}{c}74.7^{\mathrm{b}} \\
(56 / 75)\end{array}$ & $\begin{array}{c}93.9 \\
(1747 / 1861)\end{array}$ \\
\hline $\mathrm{PET} / \mathrm{CT}(\mathrm{n}=50)$ & $\begin{array}{r}46.0^{\mathrm{b}, \mathrm{d}} \\
(40 / 87)\end{array}$ & $\begin{array}{c}99.4^{\mathrm{c}} \\
(986 / 992)\end{array}$ & $\begin{array}{c}95.1^{\mathrm{c}, \mathrm{d}} \\
(1026 / 1079)\end{array}$ & $\begin{array}{c}87.0^{c} \\
(40 / 46)\end{array}$ & $\begin{array}{c}95.5^{\mathrm{a}} \\
(986 / 1033)\end{array}$ \\
\hline
\end{tabular}

PPV, positive predictive value; NPV, negative predictive value; ${ }^{\mathrm{P}}<0.05$ vs. $\mathrm{CT}$; ${ }^{\mathrm{b}} \mathrm{P}<0.01$ vs. $\mathrm{CT}$; ${ }^{\mathrm{c}} \mathrm{P}<0.001$ vs. CT and ${ }^{\mathrm{d}} \mathrm{P}<0.05$ vs. PET .
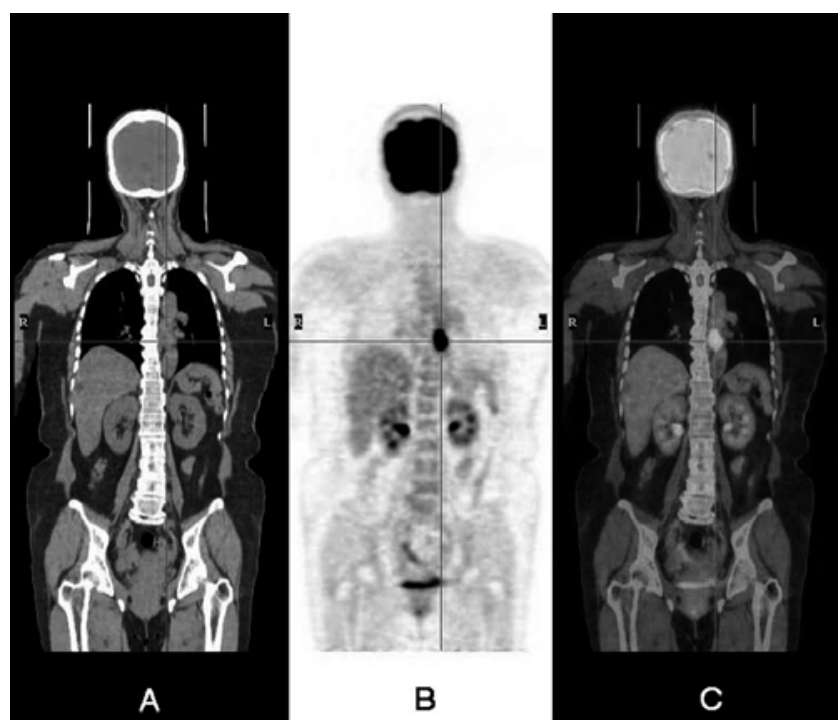

Figure 1. PET/CT imaging of a 58-year-old man with squamous cell carcinoma of the middle thoracic esophagus shows FDG uptake (SUV; 7.89) in the primary tumor. (A) CT imaging, (B) PET imaging and (C) PET/CT imaging.

and in 87 lymph node groups. For individual nodal group evaluation, PET/CT showed $46.0 \%$ sensitivity ( $<<0.01$ vs. CT and $\mathrm{p}<0.05$ vs. PET), $99.4 \%$ specificity ( $<<0.001$ vs. CT), $95.1 \%$ accuracy $(\mathrm{p}<0.001$ vs. CT and $\mathrm{p}<0.05$ vs. PET), $87.0 \%$ PPV ( $<<0.001$ vs. CT) and $95.5 \%$ NPV ( $<<0.05$ vs. CT). False-positive results were $1.0 \%(19 / 1936)$ in the PET group compared with $0.6 \%(6 / 1079)$ in the PET/CT group $(\mathrm{p}=0.2170)$. PET had a false-negative rate of $5.9 \%(114 / 1936)$ compared with 4.4\% (47/1079) in PET/CT ( $\mathrm{p}=0.0728)$.

Comparisons between CT, PET and PET/CT in detecting lymph node metastasis by each region are summarized in Table III. PET showed a high degree of sensitivity in the neck and upper thoracic and abdominal regions, compared with that in the mid- and lower thoracic regions. The findings were similar with CT scanning. However, PET/CT showed a higher sensitivity in lower thoracic regions than PET and CT ( $\mathrm{p}<0.05$ vs. CT and PET). Furthermore, PET/CT showed a higher sensitivity in the neck than $\mathrm{CT}(\mathrm{p}<0.05 \mathrm{vs}$. CT).

\section{Discussion}

In the present study, we assessed whether PET/CT would be of additional value over conventional PET images. We retrospectively studied 167 patients with thoracic esophageal SCC who received radical esophagectomy without prior treatment. There was no significant difference between PET and PET/CT in the detection rate of the primary tumor. With regard to the diagnostic accuracy for lymph node metastasis, PET/CT showed $75.9 \%$ sensitivity, $81.0 \%$ specificity and $78.0 \%$ accuracy, compared with $55.0,86.0$ and $70.1 \%$, respectively, for PET. There was no significant difference between PET/CT and PET for sensitivity, specificity and accuracy based on lymph node staging analysis. However, based on individual lymph nodal group analysis, PET/CT showed $46.0 \%$ sensitivity, $99.4 \%$ specificity and $95.1 \%$ accuracy, compared with 32.9, 98.9 and $93.1 \%$, respectively, for PET. The sensitivity and accuracy of PET/CT were significantly higher than those of PET. Furthermore, PET/CT 
Table III. Comparisons between CT, ${ }^{18} \mathrm{~F}-$ Fluorodeoxyglucose PET and PET/CT in detecting lymph node metastasis by each region.

\begin{tabular}{lcccccc}
\hline & & Neck & Upper & Mid & Lower & Abdomen \\
\hline CT $(\mathrm{n}=117)$ & Sensitivity & 29.4 & 43.8 & 30.0 & 0.0 & 31.6 \\
& Specificity & 98.0 & 91.8 & 86.6 & 100.0 & 88.6 \\
& Accuracy & 88.0 & 78.6 & 76.9 & 86.3 & 70.1 \\
PET $(\mathrm{n}=117)$ & Sensitivity & 52.9 & 50.0 & 25.0 & 6.3 & 31.6 \\
& Specificity & 97.0 & 89.4 & 93.8 & 100.0 & $100.0^{\mathrm{b}}$ \\
& Accuracy & 90.6 & 78.6 & 82.1 & 87.2 & 77.8 \\
PET/CT $(\mathrm{n}=50)$ & Sensitivity & $80.0^{\mathrm{a}}$ & 50.0 & 36.4 & $28.6^{\mathrm{a}, \mathrm{c}}$ & 50.0 \\
& Specificity & 97.5 & 85.3 & 94.9 & 97.7 & $100.0^{\mathrm{a}}$ \\
& Accuracy & 94.0 & 74.0 & 82.0 & 88.0 & 82.0 \\
\hline
\end{tabular}

${ }^{\mathrm{a}} \mathrm{P}<0.05$ vs. $\mathrm{CT}$; ${ }^{\mathrm{b}} \mathrm{P}<0.01$ vs. $\mathrm{CT}$ and ${ }^{\mathrm{c}} \mathrm{P}<0.05$ vs. PET.

showed a higher sensitivity in lower thoracic regions than PET. These results indicated that PET/CT had a higher sensitivity and accuracy than PET because PET/CT improved the FDG imaging in the initial lymph node staging of patients with esophageal cancer, particularly in neck and lower thoracic cancers. The integrated PET/CT imaging with co-registration of anatomic and functional imaging data is useful in the initial lymph node staging of patients with curative esophageal cancer, compared with PET alone. Lymph node staging (N0 vs. N1) was not significantly different, although individual lymph nodal group staging was significantly better with PET/CT. This may be the reason that lymph node staging is smaller numbers than individual lymph nodal group staging. If only one false-positive node among many lymph node groups is misdiagnosed as lymph node metastasis, the patient is diagnosed as lymph node staging (N1) in the lymph node staging analysis. However, the other excluded false-positive nodes are diagnosed as negative lymph nodes in individual lymph nodal group staging analysis. As a result, there was no statistical superiority in lymph node staging analysis in spite of the significant superiority of PET/CT over PET in individual lymph nodal group staging analysis.

A study by Bar-Shalom and colleagues in 32 patients with esophageal cancer (29), assessed the value of combined PET/CT compared with PET reviewed side-by-side with CT before and after surgery. PET/CT provided better specificity and accuracy than PET for detecting sites of esophageal cancer, especially for assessing cervical and abdominopelvic sites (29). Furthermore, PET/CT may also improve the limited specificity of PET alone because of false-positive results in infectious or inflammatory diseases $(30,36)$. In our study, PET/CT had a significantly higher sensitivity and accuracy than PET. PET/CT was also better than PET for false-negative rates rather than false-positive rates. The reason for this finding is that PET/CT can detect new lymph node metastasis adjacent to high FDG uptake compared to PET alone. More importance was placed in image fusion for interpretation of cervical and abdominopelvic sites in the previous study of
Bar-Shalom et al (29), compared to the current study. One reason for this may be related to the inclusion criteria we used in the current study. This study included only patients who underwent esophagectomy with lymph node dissection. Therefore, more advanced patients with abdominopelvic lymph node metastases were excluded from the study. A study by Yuan and colleagues (37) compared the value of reviewing combined FDG-PET/CT images with that of reviewing sideby-side PET and CT images in the diagnosis of locoregional lymph node metastases in 45 patients with thoracic esophageal squamous cell cancer. The sensitivity, accuracy and negative predictive value of PET/CT were significantly higher than those of PET for lymph node evaluation (37). As a hybrid of traditional anatomic imaging and functional imaging, PET/CT corrected $66.7 \%(10 / 15)$ of the interpretations that were false-negative on PET and resulted in a high sensitivity by providing a high-resolution structural map of anatomically crowded regions, allowing exclusion of the effects of adjacent tumors, physical motion, or uptake by adjacent organs. Corrections of false-positive interpretations also may have been related to the value of the accurate fusion and subsequent precise localization provided by PET/CT. These previous results are consistent with the present study.

In conclusion, the use of integrated PET/CT imaging with co-registration of anatomic and functional imaging data is highly useful in the initial lymph node staging of patients with curative esophageal cancer. Lymph node staging (N0 vs. N1) was not significantly different, though staging per lymph nodal group was significantly better with PET/CT. PET/CT imaging is highly recommended in the initial evaluation of patients with esophageal cancer.

\section{Acknowledgements}

We would like to thank T. Yoshida, H. Emura, M. Ohno, T. Ogasawara and Y. Saitoh for their excellent secretarial assistance. We would also like to thank T. Takahashi for her assistance with data management and biostatistical analysis during this study. 


\section{References}

1. Bar-Shalom R, Valdivia AY and Blaufox MD: PET imaging in oncology. Semin Nucl Med 30: 150-185, 2000.

2. Bares R, Klever P, Hauptmann S, et al: F-18 fluorodeoxyglucose PET in vivo evaluation of pancreatic glucose metabolism for detection of pancreatic cancer. Radiology 192: 79-86, 1994.

3. Inoue T, Kim EE, Komaki R, et al: Detecting recurrent or residual lung cancer with FDG-PET. J Nucl Med 36: 788-793, 1995.

4. Ahuja V, Coleman RE, Herndon J and Patz EF Jr: The prognostic significance of fluorodeoxyglucose positron emission tomography imaging for patients with non-small cell lung carcinoma. Cancer 83: 918-924, 1998.

5. Coleman RE: PET in lung cancer. J Nucl Med 40: 814-820, 1999.

6. Block MI, Patterson GA, Sundaresan RS, et al: Improvement in staging of esophageal cancer with the addition of positron emission tomography. Ann Thorac Surg 64: 770-776, 1997.

7. Luketich JD, Schauer PR, Meltzer CC, et al: Role of positron emission tomography in staging esophageal cancer. Ann Thorac Surg 64: 765-769, 1997.

8. Flanagan FL, Dehdashti F, Siegel BA, et al: Staging of esophageal cancer with $18 \mathrm{~F}$-fluorodeoxyglucose positron emission tomography. AJR Am J Roentgenol 168: 417-424, 1997.

9. Rankin SC, Taylor H, Cook GJ and Mason R: Computed tomography and positron emission tomography in the preoperative staging of oesophageal carcinoma. Clin Radiol 53: 659-665, 1998

10. Yeung HW, Macapinlac HA, Mazumdar M, Bains M, Finn RD and Larson SM: FDG-PET in esophageal cancer. Incremental value over computed tomography. Clin Positron Imaging 2: 255-260, 1999.

11. Flamen P, Lerut A, Van Cutsem E, et al: Utility of positron emission tomography for the staging of patients with potentially operable esophageal carcinoma. J Clin Oncol 18: 3202-3210, 2000.

12. Yoon YC, Lee KS, Shim YM, Kim BT, Kim K and Kim TS: Metastasis to regional lymph nodes in patients with esophageal squamous cell carcinoma: CT versus FDG PET for presurgical detection prospective study. Radiology 227: 764-770, 2003.

13. van Westreenen HL, Westerterp M, Bossuyt PM, et al: Systematic review of the staging performance of $18 \mathrm{~F}$-fluorodeoxyglucose positron emission tomography in esophageal cancer. J Clin Oncol 22: 3805-3812, 2004.

14. Skehan SJ, Brown AL, Thompson M, Young JE, Coates G and Nahmias C: Imaging features of primary and recurrent esophageal cancer at FDG-PET. Radiographics 20: 713-723, 2000.

15. Flamen P, Lerut A, Van Cutsem E, et al: The utility of positron emission tomography for the diagnosis and staging of recurrent esophageal cancer. J Thorac Cardiovasc Surg 120: 1085-1092, 2000.

16. Kato H, Miyazaki T, Nakajima M, Fukuchi M, Manda R and Kuwano $\mathrm{H}$ : Value of positron emission tomography in the diagnosis of recurrent oesophageal carcinoma. Br J Surg 91: 1004-1009, 2004.

17. Brucher BL, Weber W, Bauer M, et al: Neoadjuvant therapy of esophageal squamous cell carcinoma: response evaluation by positron emission tomography. Ann Surg 233: 300-309, 2001.

18. Flamen P, Van Cutsem E, Lerut A, et al: Positron emission tomography for assessment of the response to induction radiochemotherapy in locally advanced oesophageal cancer. Ann Oncol 13: 361-368, 2002.
19. Weber WA, Ott K, Becker K, et al: Prediction of response to preoperative chemotherapy in adenocarcinomas of the esophagogastric junction by metabolic imaging. J Clin Oncol 19: 3058-3065, 2001

20. Kato H, Kuwano H, Nakajima M, et al: Usefulness of positron emission tomography for assessing the response of neoadjuvant chemoradiotherapy in patients with esophageal cancer. Am J Surg 184: 279-283, 2002 .

21. Kato H, Kuwano H, Nakajima M, et al: Comparison between positron emission tomography and computed tomography in the use of the assessment of esophageal carcinoma. Cancer 94: 921-928, 2002.

22. Kato H, Miyazaki T, Nakajima M, et al: The incremental effect of positron emission tomography on diagnostic accuracy in the initial staging of esophageal carcinoma. Cancer 103: 148-156, 2005.

23. Kato H, Fukuchi M, Miyazaki T, et al: Positron emission tomography in esophageal cancer. Esophagus 2: 111-121, 2005.

24. Bar-Shalom R, Yefremov N, Guralnik L, et al: Clinical performance of $\mathrm{PET} / \mathrm{CT}$ in evaluation of cancer: additional value for diagnostic imaging and patient management. J Nucl Med 44: 1200-1209, 2003.

25. Lardinois D, Weder W, Hany TF, et al: Staging of non-small-cell lung cancer with integrated positron-emission tomography and computed tomography. N Engl J Med 348: 2500-2507, 2003.

26. Schoder H, Yeung HW, Gonen M, Kraus D and Larson SM: Head and neck cancer: clinical usefulness and accuracy of PET/CT image fusion. Radiology 231: 65-72, 2004.

27. Cohade C, Osman M, Leal J and Wahl RL: Direct comparison of 18FFDG PET and PET/CT in patients with colorectal carcinoma. J Nucl Med 44: 1797-1803, 2003.

28. Freudenberg LS, Antoch G, Schutt P, et al: FDG-PET/CT in re-staging of patients with lymphoma. Eur J Nucl Med Mol Imaging 31: 325-329, 2004.

29. Bar-Shalom R, Guralnik L, Tsalic M, et al: The additional value of PET/CT over PET in FDG imaging of oesophageal cancer. Eur J Nucl Med Mol Imaging 32: 918-924, 2005.

30. Jadvar H, Henderson RW and Conti PS: 2-deoxy-2-[F-18] fluoro-D-glucose-positron emission tomography/computed tomography imaging evaluation of esophageal cancer. Mol Imaging Biol 8: 193-200, 2006.

31. Blodgett TM, Meltzer CC and Townsend DW: PET/CT: form and function. Radiology 242: 360-385, 2007.

32. Sobin LH and Wittekind C (eds). TNM classification of malignant tumors, 6th edition. John Wiley \& Sons, New York, 2002.

33. Japanese Society for Esophageal Diseases. Guidelines for the clinical and pathological studies on carcinoma of the esophagus. 10th edition. Kanehara, Tokyo, 2007.

34. Beck JR: Likelihood ratios. Another enhancement of sensitivity and specificity. Arch Pathol Lab Med 110: 685-686, 1986.

35. Dwyer AJ: Matchmaking and McNemar in the comparison of diagnostic modalities. Radiology 178: 328-330, 1991.

36. Erasmus JJ and Munden RF: The role of integrated computed tomography positron-emission tomography in esophageal cancer: staging and assessment of therapeutic response. Semin Radiat Oncol 17: 29-37, 2007.

37. Yuan S, Yu Y, Chao KS, et al: Additional value of PET/CT over PET in assessment of locoregional lymph nodes in thoracic esophageal squamous cell cancer. J Nucl Med 47: 1255-1259, 2006. 